\title{
Diagnosis of T-cell lymphoid proliferations of the skin: putting all the pieces together
}

\author{
Carlos A. Torres-Cabala $\mathbb{1}^{1}$
}

Received: 1 July 2019 / Revised: 29 September 2019 / Accepted: 15 October 2019 / Published online: 29 October 2019

(c) The Author(s), under exclusive licence to United States \& Canadian Academy of Pathology 2019

\begin{abstract}
The spectrum of T-cell lymphoid proliferations of the skin varies from indolent to highly aggressive diseases and therefore an accurate pathological diagnosis is paramount. Integration of clinical, histopathological, immunohistochemical, and molecular findings is of crucial importance in the evaluation of these processes. In this article, we discuss selected situations where difficulty may arise for the pathologist evaluating this type of skin biopsies, such as: the diagnosis of early (patch stage) mycosis fungoides, the distinction of mycosis fungoides with large cell transformation from primary cutaneous anaplastic large cell lymphoma, the recognition of new histopathological patterns of lymphomatoid papulosis and the entities they mimic, the evaluation of primary cutaneous anaplastic large cell lymphoma with expression of markers suggestive of systemic origin (such as ALK), the awareness of the wide range of clinical and pathological presentations of hydroa vacciniforme-like EBV-positive T-cell lymphoproliferative disorders, the evaluation of cases of primary cutaneous $\gamma \delta \mathrm{T}$-cell lymphoma showing predominantly epidermotropic pattern of growth, and the correct interpretation of findings seen in indolent proliferations such as primary cutaneous acral CD8-positive T-cell lymphoma and primary cutaneous small/medium size CD4 + T-cell lymphoproliferative disorder.
\end{abstract}

\section{Introduction}

T-cell lymphoid primary proliferations of the skin have been the subject of extensive study and classification in the last few years. These diseases range from indolent solitary lesions to aggressive tumors with high mortality rates. As in other areas of dermatopathology (and probably requiring even more emphasis), the evaluation of skin biopsies in which a T-cell proliferation is identified must be done primarily in conjunction with the clinical presentation of the disease. A correct interpretation of findings in these cases works like solving a jigsaw puzzle where clinical, histological, immunohistochemical, and molecular findings are the pieces that should perfectly fit to result in a larger diagnostic picture.

The objectives of this review are: (1) to identify clues for the correct histopathological diagnosis of common T-cell

Carlos A. Torres-Cabala

ctcabala@mdanderson.org

1 Departments of Pathology and Dermatology, The University of Texas - MD Anderson Cancer Center, 1515 Holcombe Blvd Unit 85 , Houston, TX 77030, USA lymphoid proliferations of the skin, such as mycosis fungoides; (2) to integrate clinical, pathological, and molecular findings in the workup of cutaneous T-cell lymphomas; and (3) to recognize less common cutaneous T-cell lymphomas and include them in the differential diagnosis of $\mathrm{T}$-cell lymphoid proliferations of the skin.

\section{Mycosis fungoides}

\section{Early mycosis fungoides}

Mycosis fungoides (MF) is the most common cutaneous lymphoma in the US, representing almost $50 \%$ of all the cases $[1,2]$. Many variants and subtypes, both clinical and histopathological, have been described in MF. The diagnosis of early MF (patch stage) is particularly challenging and typically requires clinical-pathological correlation. This diagnosis might be elusive because MF in its early stage shares clinical and histopathological features with inflammatory benign dermatoses like parapsoriasis, eczema, lichenoid dermatoses, pityriasis lichenoides chronica, pityriasis rosea, drug eruptions, and vitiligo, among others, and immunohistochemistry and molecular analysis have limited utility as isolated criteria $[3,4]$. 
Early MF is classically described as showing disproportionate epidermotropism by atypical lymphocytes displaying cerebriform, hyperchromatic nuclei surrounded by haloes, alignment of these lymphocytes at the dermal-epidermal junction (the "string of pearls" sign) along with pagetoid upward migration, and vacuolar degeneration of the basal keratinocytes. Fibrosis of the papillary dermis and a band-like or superficial perivascular infiltrate are usually seen in the dermis. From all of the above, the presence of mononuclear cerebriform medium to large cells within the epidermis seems to be the most important histopathological feature. Unfortunately, as expected, these histopathological criteria are considered to be the most controversial and difficult to apply in the daily sign out of cases of early MF.

Ancillary studies such as immunohistochemistry may help in the diagnosis. Demonstration of loss of pan-T-cell markers, such as CD7, CD2, or CD5, is useful to interpret a T-cell proliferation as abnormal. The predominance of expression of CD4 over CD8 (or viceversa) defined as a ratio greater than 4-6:1 is also important to define the phenotype of the T-cell process and to support a neoplastic origin of it [5]. Molecular studies to evaluate TCR gene rearrangements, by PCR or sequencing, are performed in order to demonstrate the clonal nature of the lymphoid process affecting the skin.
An elegant example of the integration of clinical, histopathological, immunohistochemical, and molecular findings in the diagnosis of cutaneous T-cell lymphoid proliferations is the algorithm proposed by Pimpinelli et al. [3] and the International Society for Cutaneous Lymphomas for the diagnosis of early MF. This scoring system assigns points for clinical, histopathological, molecular biological, and immunopathological criteria. A total of four points is required for the diagnosis of MF based on any combination of these criteria (Table 1). We apply these criteria when evaluating our specimens and have found them very useful in most of the cases. Obviously, limitations inherent to the nature of these processes exist when applying these criteria, and therefore interpretation of histopathological, immunohistochemical, and molecular findings needs to be conducted with caution.

The histopathological findings of early MF can be challenging to interpret. Epidermotropism (or exocytosis by lymphocytes, a term usually applied when a reactive process is entertained in the differential diagnosis) and a superficial perivascular or lichenoid infiltrate are features present in MF but also in reactive conditions. Cytologic atypia and collections of intraepidermal lymphocytes (Pautrier microabscesses) both strongly suggest MF, but evaluation of atypia might be subjective, and Pautrier
Table 1 Pimpinelli et al. (International Society for Cutaneous Lymphoma) algorithm for diagnosis of early mycosis fungoides [3]

\begin{tabular}{|c|c|}
\hline Criteria & Scoring system \\
\hline \multicolumn{2}{|l|}{ Clinical } \\
\hline Basic & $\begin{array}{l}2 \text { points for basic criteria and } 2 \\
\text { additional criteria }\end{array}$ \\
\hline Persistent and/or progressive patches/thin plaques & $\begin{array}{l}1 \text { point for basic criteria and } 1 \\
\text { additional criterion }\end{array}$ \\
\hline \multicolumn{2}{|l|}{ Additional } \\
\hline \multicolumn{2}{|l|}{ (1) Non-sun-exposed location } \\
\hline \multicolumn{2}{|l|}{ (2) Size/shape variation } \\
\hline \multicolumn{2}{|l|}{ (3) Poikiloderma } \\
\hline \multicolumn{2}{|l|}{ Histopathological } \\
\hline Basic & $\begin{array}{l}2 \text { points for basic criteria and } 2 \\
\text { additional criteria }\end{array}$ \\
\hline Superficial lymphoid infiltrate & $\begin{array}{l}1 \text { point for basic criteria and } 1 \\
\text { additional criterion }\end{array}$ \\
\hline \multicolumn{2}{|l|}{ Additional } \\
\hline \multicolumn{2}{|l|}{ (1) Epidermotropism without spongiosis } \\
\hline \multicolumn{2}{|l|}{ (2) Lymphocytic atypia } \\
\hline \multicolumn{2}{|l|}{ Molecular biological } \\
\hline (1) Clonal T-cell receptor gene rearrangement & 1 point for clonality \\
\hline \multicolumn{2}{|l|}{ Immunopathological (immunohistochemical) } \\
\hline (1) $<50 \% \mathrm{CD} 2+, \mathrm{CD} 3+$, and/or CD5+ T cells & 1 point for one or more criteria \\
\hline \multicolumn{2}{|l|}{$(2)<10 \% \mathrm{CD} 7+\mathrm{T}$ cells } \\
\hline $\begin{array}{l}\text { (3) Epidermal/dermal discordance of CD2, CD3, CD5, or CD7 (T-cell } \\
\text { antigen deficiency confined to the epidermis) }\end{array}$ & \\
\hline
\end{tabular}


microabscesses are not always present in early stages of MF [6]. In addition, although some descriptions of classic MF indicate that epidermal findings such as spongiosis, interface changes, or marked verrucous acanthosis are not present in MF, all these can be certainly seen in the different variants of the disease. However, marked spongiosis, true lichenoid interface dermatitis pattern, vacuolization of epidermal junction, apoptotic keratinocytes, edema of papillary dermis, and presence of large numbers of eosinophils and extravasation of erythrocytes should all be interpreted by the pathologist as unusual changes of MF and indicative of a reactive process.

As with the histological findings, caution must be exerted when evaluating the immunohistochemical expression of T-cell markers in early MF. The utility of immunohistochemistry in early lesions of MF has been somewhat controversial [7]. When examining immunohistochemical studies in possible early MF, it is advisable to focus on the atypical lymphocytes, which in many cases are better seen within the epidermis. Estimation of $\mathrm{CD} 4$ to $\mathrm{CD} 8$ ratio should take in consideration the expression of CD4 by Langerhans cells and histiocytes. In our daily practice, we have encountered cases erroneously interpreted as CD4positive proliferations based on the apparent predominance of CD4-positive cells in the infiltrate. Close examination reveals that many of the CD4-positive cells are indeed histiocytes or intraepidermal Langerhans cells. It is important to also take into account that diminished CD7 expression can be seen in 10-20\% of inflammatory dermatoses and therefore lacks specificity for MF [8].

PCR-based molecular studies used to evaluate TCR gene rearrangements in early lesions of MF have 50-60\% sensitivity and low specificity, with some authors reporting even lower frequencies [9]. Sequencing-based studies may yield higher sensitivity and specificity values, but in general a clonal T-cell population demonstrated by molecular studies does not necessarily mean that the lesion is a lymphoma, especially if we consider that some reactive T-cell processes can be monoclonal [10]. The identification of identical clones in two biopsies from different anatomic locations or in skin samples taken at various points in time is generally considered as a strong evidence of clonality [11].

The utility of Pimpinelli's scoring system in the diagnosis of early MF has been validated by others [4]. Compared with clinicopathological inflammatory mimickers, most of MF cases reached the four-point threshold for diagnosis. Epidermotropism without spongiosis and lymphoid atypia were present in $87.5 \%$ and $58.3 \%$ of MF cases, respectively, and in $70 \%$ and $30 \%$ of MF mimickers. Of the immunophenotypic alterations, the most common aberrancy in cases and controls was diminished expression of CD7; however, no control cases showed diminished expression of
$\mathrm{CD} 2, \mathrm{CD} 3$, and/or CD5 or displayed epidermal/dermal discordance in the expression of T-cell markers. The same study found clonal rearrangement in $42 \%$ of MF cases and $30 \%$ of controls. The final sensitivity of the four-point threshold for a diagnosis of early MF was $87.5 \%$ and the specificity was $60 \%$ in the above-referenced study.

Drug reactions constitute a particularly difficult differential diagnosis of early MF [12]. As with other inflammatory conditions, histopathological findings that may help in the distinction of these processes from early MF include the presence of numerous eosinophils, necrotic/apoptotic keratinocytes, and signs of urticaria. Cytologically atypical lymphocytes can be present in drug-associated reactions. By immunohistochemistry, the T-cell drug reactions usually lack predominance of either CD4 or CD8 expression, but may be CD8-positive, and rarely CD4-positive (Fig. 1). Although these reactions are most commonly polyclonal by molecular studies, monoclonal proliferations induced by drugs have been described. Drug reactions can be caused by anticonvulsants, antidepressants, ACE inhibitors, antihistaminics, and monoclonal antibodies, among others. Many times, the clinical history of a new medication helps, and the diagnosis is confirmed if the lesions regress when the drug is discontinued. However, a temporal relationship between initiation of therapy and onset of the cutaneous lesions is not always clearly determined.

The identification of a marker that can reliably distinguish early MF from its inflammatory mimickers has been elusive. Thymocyte selection-associated HMG box protein (TOX) encodes a high-mobility group family (HMG) domain DNA binding nuclear protein, which regulates the differentiation of developing T-cells, and is normally suppressed in peripheral lymphoid tissues. TOX is aberrantly detected and overexpressed in CD4-positive T cells in MF, and appears to correlate with lesion thickness, and increased risks of progression and disease specific-mortality [13]. The immunohistochemical expression of TOX has been reported to be useful in the distinction between early MF and reactive conditions [14]. TOX appears to be a good marker for MF, when the expression is strong $(86.3 \%$ sensitivity, 75.0\% specificity, PPV: 97\%). Levels of TOX can also be detected by qPCR and immunofluorescence [15]. Interestingly, GATA-3, a marker of Th2 differentiation frequently expressed in MF, appears to regulate TOX [16]. The same pattern of expression of TOX has been detected in both MF and large plaque parapsoriasis, supporting the contention that these two processes are closely related [16].

Cell adhesion molecule 1 (CADM1) is a tumor suppressor gene in non-small cell lung carcinoma that has been reported as a diagnostic marker in adult T-cell leukemia lymphoma. CADM1 is positive in a subset of B cells, monocytes, and neutrophils, but normal $\mathrm{T}$ lymphocytes are 

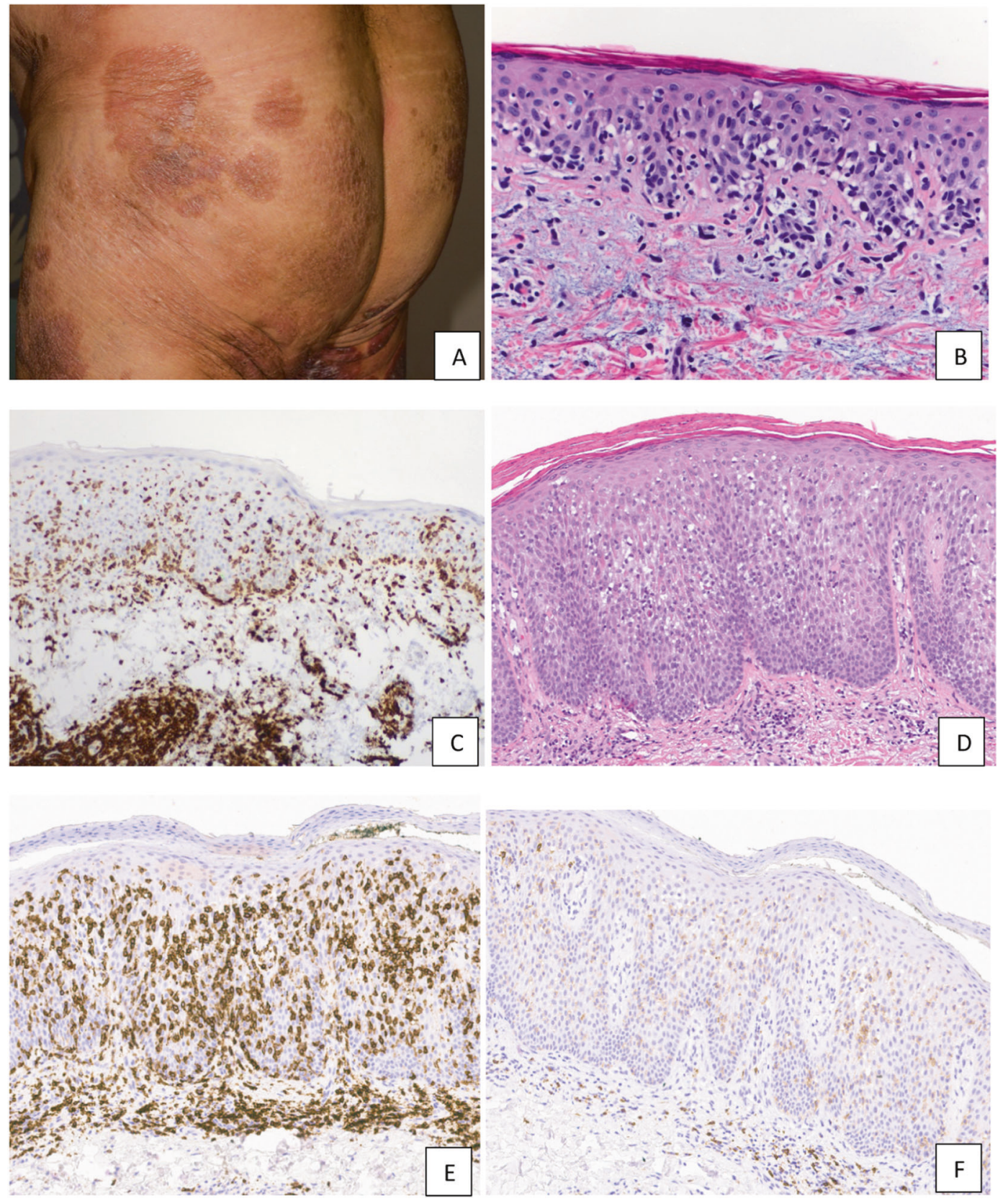

Fig. 1 Mycosis fungoides, early (patch) lesion and drug reactions may share a similar histopathological appearance. a Mycosis fungoides. Clinical presentation of long-standing eczematous lesions on non-sunexposed areas should be correlated with pathological findings. b Mycosis fungoides. A mild lymphocytic infiltrate with marked epidermotropism is noted on histology. The lymphocytes reveal nuclear atypia and align along the dermal-epidermal junction (H\&E, $\times 200$ ). c Mycosis fungoides. CD3 highlights the epidermotropic lymphocytes (immunoperoxidase, $\times 100$ ). d A lymphomatous drug

reaction revealing marked lymphocyte exocytosis and some spongiosis. In the absence of clinical information, the histopathological findings may be misinterpreted as those of mycosis fungoides $(\mathrm{H} \& \mathrm{E}$, $\times 100$ ). e Drug reaction. CD3 labels the numerous intraepidermal lymphocytes (immunoperoxidase, $\times 100$ ). f Drug reaction. Most of the lymphocytes, including the intraepidermal cells, are weakly positive for CD8 and negative for CD4 (not shown). Most drug reactions exhibit positivity for CD8 (immunoperoxidase, $\times 100$ )

negative for CADM1. A recent study [17] found that $94.8 \%$ of MF cases were positive while no reactive dermatitides showed positivity for CADM1 by immunohistochemistry. It has to be pointed out that a low cutoff of $5 \%$ and a double immunohistochemistry with CD4 was performed in the referenced study, potentially limiting the practical application of this marker.

Fibrinogen-like protein 2 (FGL-2) is a serin protease that cleaves prothrombin into thrombin. FGL-2 is expressed on the surface of monocytes/activated macrophages and 
endothelial cells and is secreted by peripheral blood CD4 + CD8 + cells. It has been reported to be increased in various types of solid tumors. FGL-2 protein activity has been tested as a potential biomarker for diagnosis of early MF by studying its activity in peripheral blood mononuclear cells of patients with MF and comparing it with healthy controls and patients with inflammatory dermatoses [18]. The early MF subgroup showed 1.4 fold higher FGL-2 activity compared with that of patients with inflammatory dermatoses, making this blood test a potential marker for early MF.

Besides the new and exciting potential biomarkers for diagnosis of early MF, it is necessary to emphasize that communication with the treating physician is key for an adequate diagnosis and subsequent management of these patients. Multiple biopsies, taken from old and new lesions, are sometimes needed for definitive diagnosis. It is also recommended to stop any topical treatment 2-4 weeks prior to the time of biopsy, in order to minimize therapy effect on the examined specimens. Clinical-pathological correlation remains the gold standard for diagnosis of early $\mathrm{MF}$.

\section{Advanced mycosis fungoides}

Plaque and tumor lesions of MF are usually not difficult to recognize as lymphomatous processes on biopsies. In the setting of a patient with a clinical history compatible with MF, that is, long-standing lesions on non-sundamaged skin, the diagnosis is evident if the histopathological findings are those of a T-cell proliferation with various degrees of epidermotropism (or adnexotropism, in the less common folliculotropic or syringotropic variants of MF). Regarding immunophenotype, as in early MF, besides the most common $\mathrm{CD} 4+$, unusual phenotypes such as CD8+, double-positive CD4/CD8 or doublenegative CD4/CD8 may be encountered [19-21]. The phenomenon of phenotype switching (CD4 to CD8 or viceversa), although rarely reported, may not be as uncommon as we think and should be considered before making a diagnosis of a new lymphoma in the setting of a history of MF [22].

Tumor lesions of MF may show ulceration and only minimal epidermotropism, making the diagnosis less straightforward when clinical information is absent or minimal. Large cell transformation of MF, defined as more than $25 \%$ of the infiltrate displaying large cell cytology (four times or more the size of a normal histiocyte), may confer the tumor an appearance that is histopathologically indistinguishable from that of anaplastic large cell lymphoma (ALCL). No histopathological findings alone can determine whether the tumor corresponds to large cell transformation of MF or ALCL. Loss of expression of panT-cell markers such as CD3, CD5, or CD2 has been regarded to suggest ALCL rather than MF with large cell transformation [23]. Similarly, the expression of cytotoxic markers such as perforin may indicate that the tumor corresponds to ALCL. It has been reported that immunohistochemical expression of GATA-3, a regulator of Th2 differentiation, may favor MF with large cell transformation since cases of ALCL tend to be negative for this marker [24]. In our hands, only a combination of clinical information and a panel of immunohistochemical markers may help in the distinction of MF with large cell transformation and ALCL (Fig. 2). It is important to emphasize that large transformation of MF is most of the times diagnosed in the setting of a patient with a known history of MF while patients with ALCL may lack such a history. Distinction of the two entities, based on clinical-pathological correlation, is extremely important since the two entities differ greatly in prognosis.

\section{Non-MF cutaneous T-cell lymphomas and lymphoproliferative disorders}

The 2018 revision of the WHO-EORTC classification of cutaneous lymphomas introduces new entities and redefines old categories among the T-cell lymphoid proliferations in the skin [2]. New subtypes of lymphomatoid papulosis based on histopathological/immunophenotypic features have been included. Primary cutaneous $\gamma \delta$ T-cell lymphoma is considered a definitive category, along with primary cutaneous acral CD8 + T-cell lymphoma. The name of hydroa vacciniforme-like EBV-positive lymphoma was changed to lymphoproliferative disorder since it is recognized to exhibit a spectrum of clinical presentations and outcomes. Primary cutaneous small/medium CD4+ T-cell lymphoproliferative disorder was also downgraded from lymphoma in view of its excellent prognosis and presentation as a localized disease. In this section, we review selected non-MF cutaneous T-cell lymphomas and lymphoproliferative disorders for which updates or changes were made in the 2018 revision of the WHO-EORTC classification.

\section{CD30-positive T-cell lymphoproliferative disorders}

\section{Lymphomatoid papulosis}

The new subtypes of lymphomatoid papulosis (LyP) described in the last few years bear importance because of their histopathological similarities with other hematolymphoid conditions involving the skin, making the differential diagnosis of these entities sometimes difficult. LyP is a partially understood lymphoproliferative disorder. It presents with grouped or disseminated papules/nodules that regress spontaneously within weeks or months. The main 

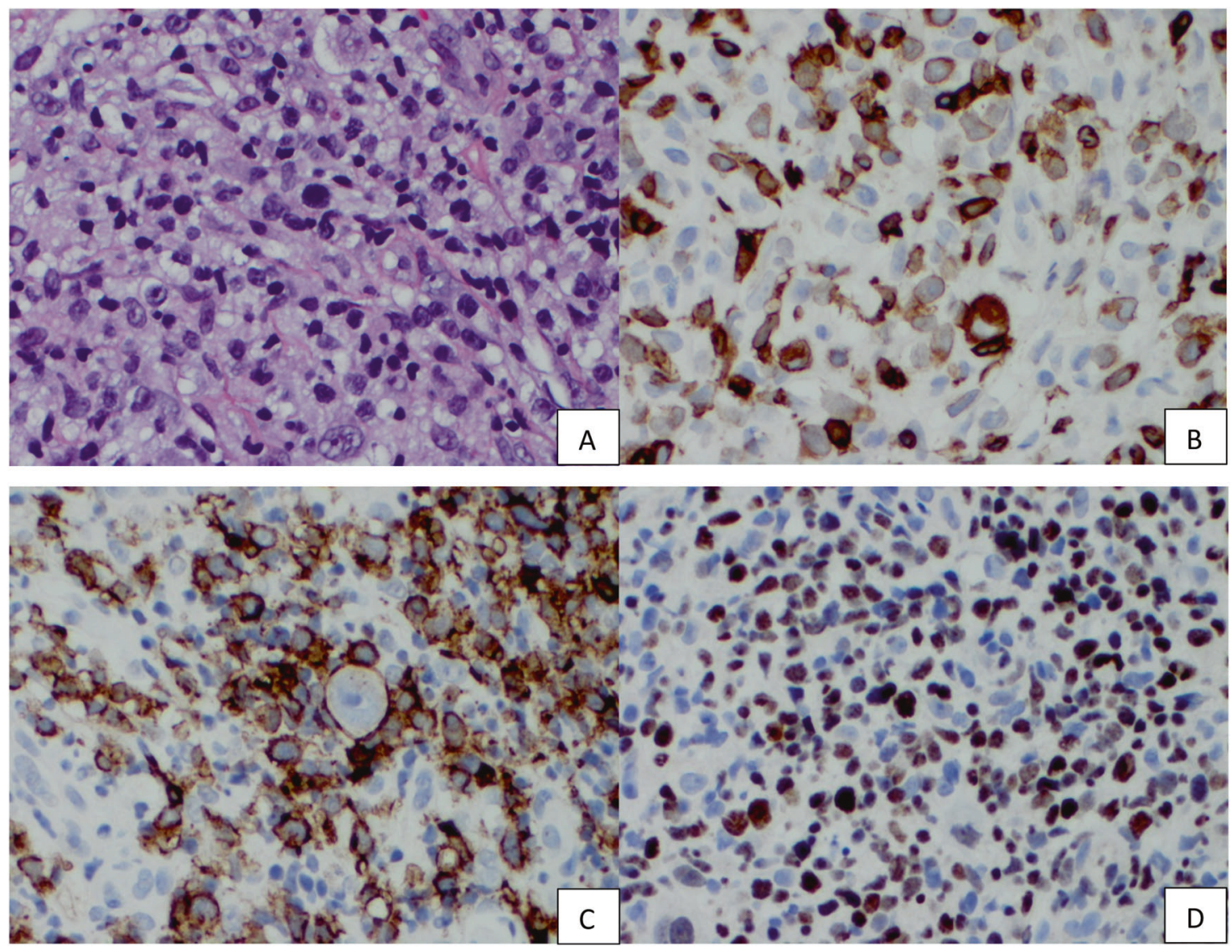

Fig. 2 Mycosis fungoides with large cell transformation may be histologically indistinguishable from primary cutaneous anaplastic large cell lymphoma. a Morphological appearance of a tumor lesion from a patient with no known history of mycosis fungoides. Large pleomorphic cells, some of them anaplastic, constitute most of the infiltrate. In cases in which clinical history of mycosis fungoides is lacking, primary cutaneous anaplastic large cell lymphoma is a diagnostic possibility $(\mathrm{H} \& \mathrm{E}, \times 200)$. b The large cells are positive for CD3. Notice that some of the cells appear to have lost expression of the

phenotypical feature in all LyP types is the constant expression of CD30 by the atypical T cells, except in some cases of LyP type B. There is variable expression of pan-Tcell markers such as CD2, CD3, CD5, and CD7. The atypical lymphocytes are $\mathrm{CD} 4+$, with the exception of the types $\mathrm{D}$ and some cases of type $\mathrm{E}$. The lesions express CD56 and cytotoxic markers in a variable percentage of cases [25]. Type A LyP is classically regarded as "Hodgkinlike" based on its histomorphological appearance where scattered large $\mathrm{CD} 30+$ atypical cells are present in a background of numerous small lymphocytes, neutrophils, and eosinophils. Type B, so-called "MF-like" is characterized by small to medium-sized atypical cells with irregular nuclei, scant inflammatory background and epidermotropism, and sometimes negative expression of CD30. Type C LyP, or "ALCL-like" is composed of sheets of large pleomorphic or anaplastic atypical cells against a background of inflammatory cells. marker (immunoperoxidase, $\times 200$ ). $\mathbf{c}$ CD30 is expressed by the atypical cells, in a percentage greater than $75 \%$. This finding alone is suggestive of anaplastic large cell lymphoma (immunoperoxidase, $\times 200$ ). d However, in this case, GATA-3 reveals diffuse nuclear positivity, favoring a diagnosis of mycosis fungoides with large cell transformation. Additional clinical history revealed that the patient presented with lesions compatible with mycosis fungoides for several months prior to medical consultation (immunoperoxidase, $\times 200$ )

Special attention should be put on the more recently described LyP type D [26], or "primary cutaneous aggressive epidermotropic CD8+ (Berti) T-cell lymphoma-like". A prime example of clinical-pathological correlation is indeed the differential diagnosis among LyP type D and Berti lymphoma [27]. A case referred to our institution with the diagnosis of primary cutaneous aggressive epidermotropic CD8+ T-cell lymphoma was reviewed along with a new inhouse biopsy. An epidermotropic pandermal infiltrate composed of atypical cells in the absence of inflammatory background was identified. The infiltrate revealed cytologic atypia and diffuse expression of CD8. However, CD30 labeling was strong and diffuse, a finding rarely present in primary cutaneous aggressive epidermotropic CD8+ T-cell lymphoma. More importantly, on clinical examination, the patient presented with a history of recurrent multiple small papules, some of them ulcerated, with spontaneous healing (Fig. 3). A diagnosis of LyP type D was rendered in this 

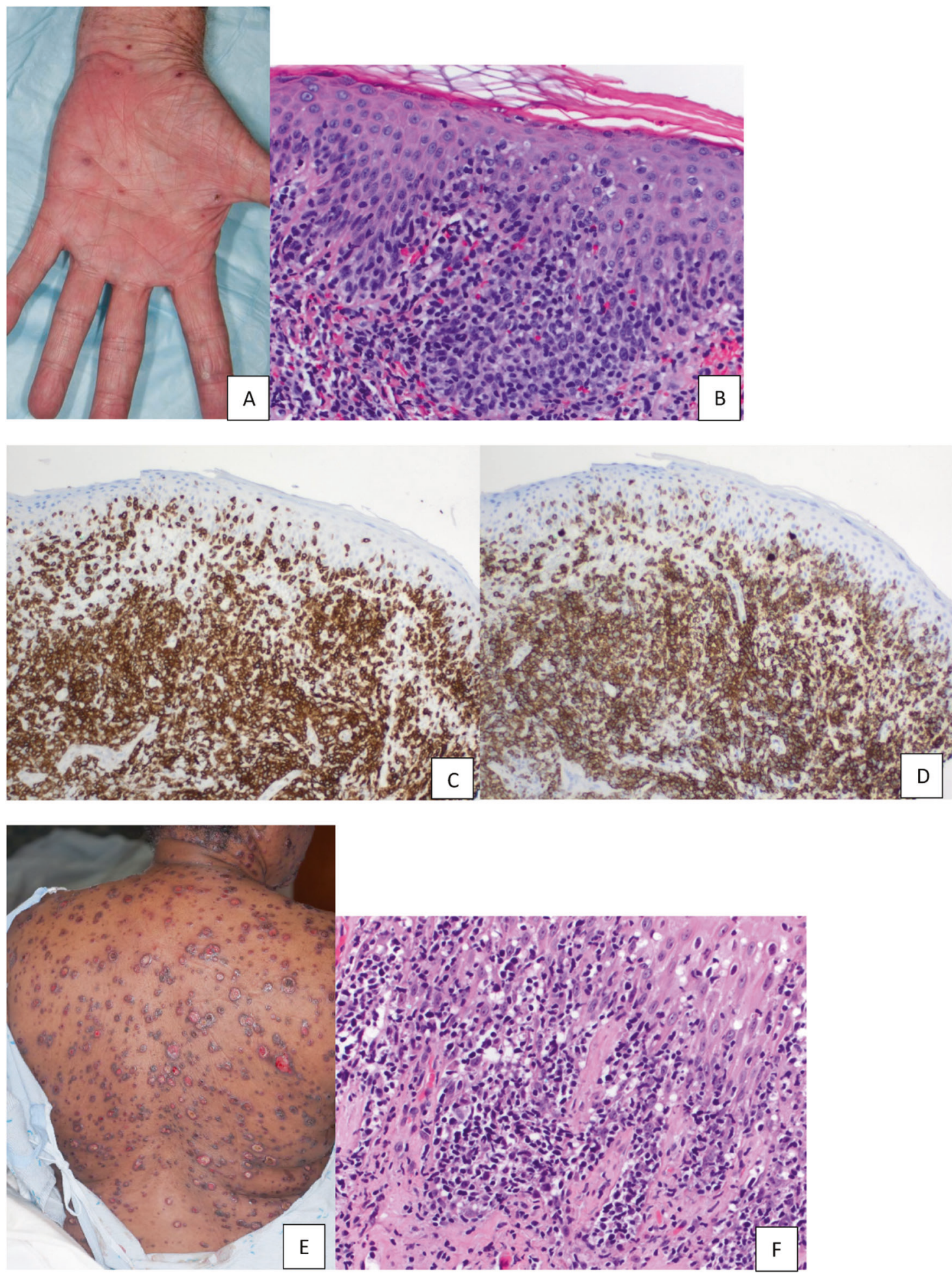

Fig. 3 Lymphomatoid papulosis type D and primary cutaneous aggressive epidermotropic CD8+ (Berti's) T-cell lymphoma are histopathologically similar. a Clinical presentation of LyP type D. Small papules, some of them ulcerated, on a patient originally diagnosed as Berti's lymphoma. b Epidermotropism by atypical lymphocytes is noted $(\mathrm{H} \& \mathrm{E}, \times 200)$. c The infiltrate is composed of CD3-positive $\mathrm{T}$ cells. The epidermotropic cells are highlighted by the immunohistochemical study (immunoperoxidase, $\times 100$ ). d Diffuse CD8 expression is noted in this lesion. In the absence of clinical information, an epidermotropic CD8 + lymphoma, such as Berti's is possible (immunoperoxidase, $\times 100$ ). e In contrast to the clinical presentation of lymphomatoid papulosis type $\mathrm{D}$, primary cutaneous aggressive epidermotropic CD8+ T-cell lymphoma patients present with rapidly growing, ulcerated lesions that do not regress (immunoperoxidase, $\times 100$ ). $f$ Marked epidermotropism by atypical lymphocytes is present. Histologically, the picture may be confused with lymphomatoid papulosis type D (H\&E, $\times 200)$ 
case, with obvious consequences for therapy and prognosis of the patient, considering the usually ominous outcome of the rare primary cutaneous aggressive epidermotropic CD8+ T-cell lymphoma [28, 29]. Epidermotropism is not uncommon in LyP and appears to be particularly frequent in LyP type $\mathrm{D}$, a finding that should not be interpreted as a sign of aggressive behavior of the lesion. Some cases of LyP type D showing $\gamma \delta$ phenotype have been described, expanding the differential diagnosis of these lesions to primary cutaneous $\gamma \delta$ T-cell lymphomas [30].

Type E LyP is characterized by angioinvasion and necrosis, making it histopathologically similar to aggressive lymphomas, such as extranodal NK/T-cell lymphoma [31]. The infiltrate is composed of medium size pleomorphic lymphocytes, commonly accompanied by thrombi, vascular occlusion, and hemorrhage. These lesions can sometimes be CD8 + but are consistently negative for EBV (EBER) in situ hybridization. Clinically, they tend to present with oligolesional papules that may progress to large necrotic ulcers. Although clinically atypical for LyP, these lesions spontaneously regress most of the time and the prognosis is excellent.

A variant of LyP with folliculocentric pattern of growth was reported a long time ago [32] and called "type F" by some. These lesions may be confused with folliculitis and eosinophilic folliculitis. Cases of LyP harboring chromosomal rearrangements of the DUSP22-IRF4 locus on 6 p25.3 have been recently reported. These lesions reveal a biphasic pattern of growth with large cells in deeper portions of the infiltrate and small cells involving the epidermis. CD30 labeling also follows a biphenotypic pattern. Distinction from more aggressive processes, such as MF with large cell transformation is again greatly helped by the clinical presentation of recurrent and self-healing papules and nodules [33].

Awareness of the different morphological appearances of LyP and the fact that sometimes they may exhibit features seen in aggressive lymphomas (i.e., angioinvasion, epidermotropism, intralymphatic involvement, $\gamma \delta$ phenotype) is the main practical advantage of classifying LyP in various subtypes. Also, it is important to remember that expression of CD30, which only indicates activation of immune cells, can be detected in a wide range of processes, neoplastic and reactive, and should not be interpreted in isolation from other histopathological and clinical findings. LyP remains as a primarily indolent process. None of the variants described so far have been demonstrated to harbor different prognostic or therapeutic implications [34].

\section{Primary cutaneous anaplastic large cell lymphoma}

Primary cutaneous ALCL (PC-ALCL) constitutes the malignant end of the spectrum of CD30-positive T-cell lymphoproliferative disorders. This tumor usually affects males in their sixties but is not uncommon in children. Clinical presentation distinguishes it from LyP since these are usually solitary tumors occurring on the head and neck and extremities. Approximately $20 \%$ of the cases are multifocal [35]. Histologically, the tumor cells are pleomorphic, anaplastic, or immunoblastic, display abundant pale cytoplasm, large irregular nuclei, one or more nucleoli, and express CD30 in more than $75 \%$ of the neoplastic T-cell population. The tumor frequently involves deep dermis and subcutis. Many rare variants have been described, such as neutrophil-rich, keratoacanthoma like, angiocentric/angiodestructive, small cell and sarcomatoid, all of them posing a diagnostic challenge and therefore should always be considered. Immunophenotypically, these tumors show variable expression of $\mathrm{CD} 2, \mathrm{CD} 3, \mathrm{CD} 4, \mathrm{CD} 5$, and cytotoxic markers, while EMA and ALK are usually negative. PC-ALCL most of the times reveals a favorable prognosis behavior and better prognosis than systemic ALCL.

Distinguishing C-ALCL from systemic ALCL has important therapeutic and prognostic implications. Traditionally, immunohistochemical expression of EMA and ALK has been considered as strongly suggestive of systemic ALCL. While most of PC-ALCLs are negative for ALK, reports of ALK-positive PC-ALCL indicate that ALK positivity does not always equal systemic ALCL [36]. Most cases of ALK + PC-ALCL behave in an indolent fashion, suggesting that these tumors are not the first manifestation of systemic ALCL [37]. The differential diagnosis of PCALCL, besides systemic ALCL, includes LyP type C, MF with large cell transformation, and peripheral T-cell lymphoma no otherwise specified (PTCL-NOS), among others. Clinical presentation and immunohistochemical profile (as already mentioned in the differential diagnosis between MF with large cell transformation and PC-ALCL) help in this situation.

\section{Hydroa vacciniforme-like EBV-positive lymphoproliferative disorder}

Hydroa vacciniforme-like EBV-positive lymphoproliferative disorder (HV-LPD) designates a group of lymphoid proliferations associated with chronic active EBV infection. Chronic active EBV infection is a term that encompasses both severe mosquito bite allergy and HV-LPD. The current thinking is that HV-LPD is a spectrum that includes classic $\mathrm{HV}$, intermediate forms, and HV-like T-cell lymphoma [38], although some controversy still exists since HV and HV-like T-cell lymphoma have very different presentations, affect distinct ethnic populations, and no progression from HV to HV-like T-cell lymphoma has been demonstrated to date. The initial descriptions of the disorder focused on pediatric cases from EBV endemic areas like Mexico, Peru, 
and Bolivia [39, 40], presenting with facial edema, HV-like lesions (papules that evolve to blisters that end in scars), and poor prognosis. Since then, the spectrum of clinical presentations has been expanded to adults. It appears that adults present with more localized lesions while pediatric cases tend to be more disseminated and that adults are more likely to present with "atypical manifestations" (such as less frequent facial swelling) than children [41].

Histopathologically, biopsies taken from patients with HV-LPD reveal dermal superficial and deep lymphocytic infiltrates of variable density showing frequent extension into the subcutis. The infiltrate is composed of small lymphocytes with mild to moderate cytologic atypia. Expression of $\mathrm{CD} 3, \mathrm{CD} 8, \mathrm{CD} 30$, and cytotoxic markers is common, along with positivity for EBER by in situ hybridization (Fig. 4). These findings may lead the pathologist to a diagnosis of extranodal NK/T-cell lymphoma. Awareness of the clinical presentation is extremely helpful. Prognosis is variable as expected from a category that includes indolent processes and frank lymphomas. It appears that prognosis differs between cases with pre-existing severe HV and cases presenting de novo [42], and that adult onset may be associated with worse outcome. The 2016 revision separates HV-LPD from systemic EBV + T-cell lymphoma of childhood, in which patients clinically present with systemic lymphoma.

\section{Primary cutaneous $\gamma \delta$ T-cell lymphoma}

Primary cutaneous $\gamma \delta$ T-cell lymphoma (PC $\gamma \delta T C L)$ is a definitive category in the 2018 revision of the WHOEORTC classification. This is a rare primary cutaneous lymphoma that affects adults and commonly shows poor prognosis, with a 5-year survival rate of $33 \%$. The typical (or "classic") presentation is that of a rapidly growing tumor that ulcerates and disseminates to other cutaneous and
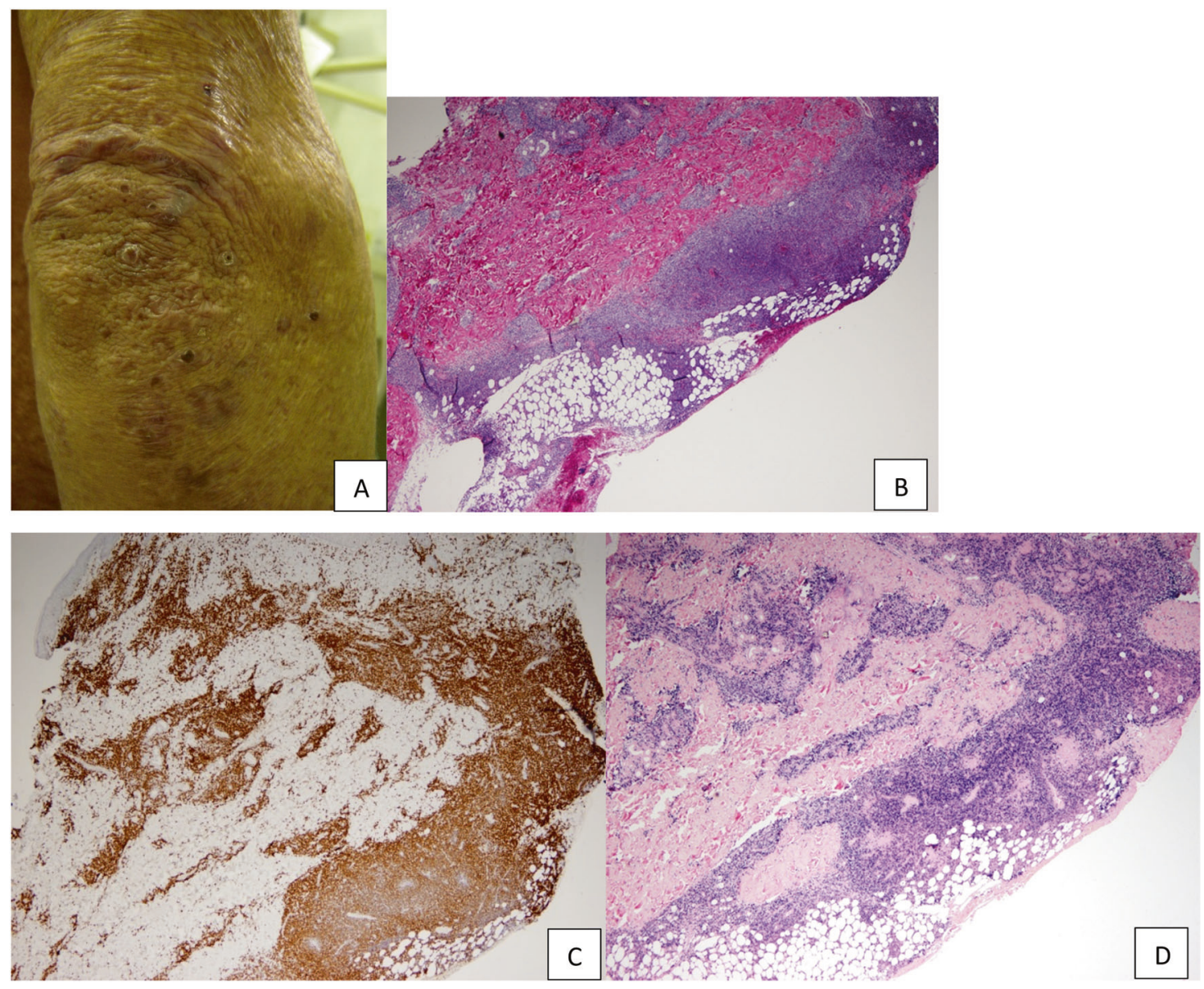

Fig. 4 Hydroa vacciniforme-like EBV-positive lymphoproliferative disorder in a Peruvian adult patient. Despite the worrisome histopathological findings observed in his skin biopsies, the patient presented with a protracted course for many years. a Blistering lesions with scarring are seen on sun-exposed areas (clinical photo courtesy of Francisco Bravo, MD). b The histopathological findings are concerning for cutaneous lymphoma, in view of the dense infiltration of small to medium size lymphocytes within the subcutaneous adipose tissue $(\mathrm{H} \& \mathrm{E}, \times 40)$. c The infiltrate is composed of CD3-positive, CD8positive (not shown) T-cells (immunoperoxidase, $\times 40$ ). d EBER in situ hybridization reveals diffuse positivity in the lesion cells (in situ hybridization, $\times 40$ ) (immunohistochemical and in situ hybridization studies performed at Laboratory of Pathology, National Cancer Institute, Bethesda, Md, courtesy of Elaine Jaffe, MD) 
extracutaneous locations [43]. In histology, the tumor reveals a dense infiltrate composed of medium to large size cells displaying irregular nuclei. Features associated with cytotoxicity such as hemorrhage and interface changes are commonly seen. The typical cases involve dermis and subcutis, with variable extension of the infiltrate within the epidermis, features that help in the differential diagnosis with subcutaneous panniculitis-like T-cell lymphoma [44]. Immunophenotypically, the atypical lymphocytes express CD3 but are double negative for CD4 and CD8, although some cases may be CD8-positive. CD56 is usually positive, along with cytotoxic markers such as TIA-1, granzyme B, and perforin. In contrast to MF, CD7 expression is likely retained, while loss of CD5 is commonly seen. The $\gamma \delta$ phenotype of the atypical cells is confirmed by expression of TCR $\delta$ or TCR $\gamma$ and lack of expression of $\beta \mathrm{F} 1$ (TCR $\beta)$. EBER in situ hydridization is negative.
Predominantly epidermotropic variants of PC $\gamma \delta \mathrm{TCL}$ pose a challenge in diagnosis since they may show a bland histopathological appearance [45] and simulate early MF, both clinically and histopathologically (Fig. 5). In fact, there is no current consensus on whether these lesions should be called epidermotropic PC $\gamma \delta \mathrm{TCL}$ or MF with $\gamma \delta$ phenotype. Examination of our series of cases revealed that although predominantly epidermotropic PC $\gamma \delta \mathrm{TCL}$ shows a better prognosis than "classic" (dermal/subcutaneous) PC $\gamma \delta T C L$, lesions exhibiting features of predominantly epidermotropic PC $\gamma \delta T C L$ tend to do worse than typical MF [46]. Moreover, evaluation of markers of Th differentiation rendered differences between epidermotropic PC $\gamma \delta T C L$ and MF, since no cases of epidermotropic PC $\gamma \delta T C L$ expressed CCR4, a Th2 marker, in contrast to cases of MF [47]. The demonstration of lack of Th2 phenotype in epidermotropic PC $\gamma \delta \mathrm{TCL}$, along with a more aggressive behavior
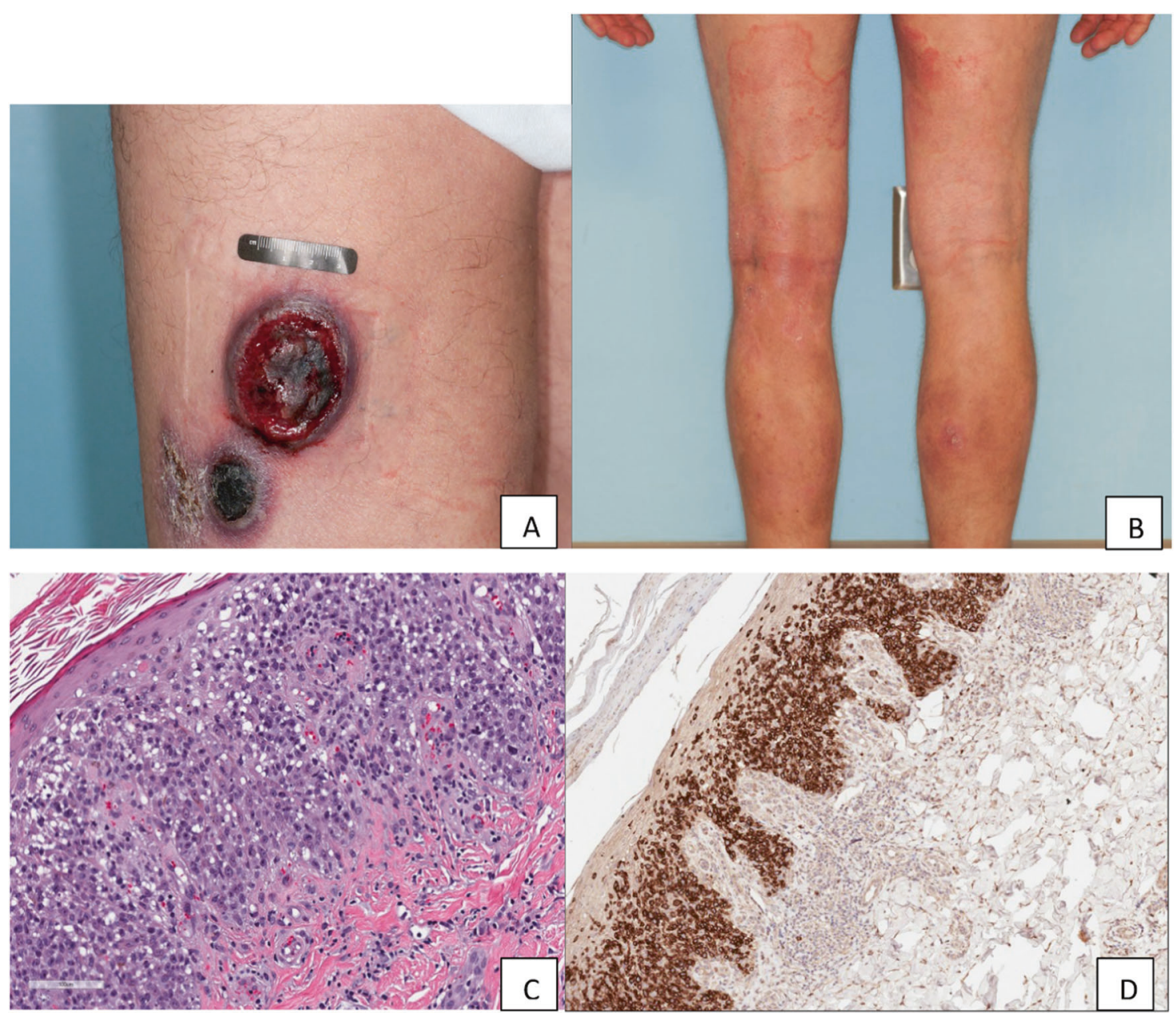

Fig. 5 Primary cutaneous $\gamma \delta$ T-cell lymphoma. a The typical clinical presentation of this lymphoma is that of rapidly growing hemorrhagic ulcerated tumor nodules. Histopathologically, involvement of the dermis and subcutaneous adipose tissue is observed. b In contrast, predominantly epidermotropic primary cutaneous $\gamma \delta \mathrm{T}$-cell lymphoma may present with lesions clinically similar to mycosis fungoides. c Histological examination of the case shown in b reveals a markedly epidermotropic infiltrate composed of atypical lymphocytes. Notice some dyskeratotic keratinocytes and hemorrhage, indicative of cytotoxicity $(\mathrm{H} \& \mathrm{E}, \times 200)$. d. The atypical lymphocytes are positive for $\mathrm{TCR} \gamma$, in contrast to the scattered reactive lymphocytes seen in the superficial dermis (immunoperoxidase, $\times 100$ ) 
compared with typical MF, supports the contention that epidermotropic PC $\gamma \delta T C L$ are distinct from MF. Interestingly, cases of long-standing MF have been observed to apparently progress into more aggressive lymphomas with $\gamma \delta$ phenotype. Immunophenotypic switching has been demonstrated in PC $\gamma \delta \mathrm{TCL}$, suggesting antigen modulation in the pathogenesis of these tumors [48].

\section{Primary cutaneous acral CD8-positive T-cell lymphoma}

This new category of tumors was initially described as "indolent CD8 + lymphoid proliferation of the ear" [49], a term that may be more appropriate in view of its overall benign behavior. Following the description of cases exclusively located on the ears, tumors involving extrafacial locations were reported, especially on acral sites. In general, the lesion presents as solitary circumscribed tumors that respond very well to local therapy.

Primary cutaneous acral CD8-positive T-cell lymphoma (PCACD8 + TCL) presents histologically as a dense proliferation of medium-sized T-cells sometimes displaying marked atypia that is positive for $\mathrm{CD} 3$ and CD8 and negative for CD4 and CD30. Variable loss of $\mathrm{CD} 2, \mathrm{CD} 5$, and $\mathrm{CD} 7$ has been reported, along with a peculiar dot-like expression of CD68 [2]. The tumor cells are usually positive for the cytotoxic marker TIA-1 but negative for granzyme B and perforin, indicating a nonactivated cytotoxic status.

In view of its indolent clinical course, it has been proposed that these tumors might be considered part of the spectrum of "primary cutaneous small to medium-sized lymphoproliferative disorders (CD4+ or CD8+)" or a CD8positive variant of primary cutaneous small/medium CD4+ T-cell lymphoproliferative disorder [50].

\section{Primary cutaneous small/medium size CD4 + T-cell lymphoproliferative disorder}

This somewhat controversial entity remains as a provisional category in the WHO-EORTC classification of cutaneous lymphomas, updated from "lymphoma" to "lymphoproliferative disorder". Clinically, it usually presents as a solitary nodule or plaque on the head and neck regions that responds to local therapy and has an excellent prognosis [51]. Histopathologically, a dense diffuse or nodular infiltrate composed of small to medium size lymphocytes with occasional large cells is present [52]. The infiltrate is composed of $\mathrm{CD} 3$-positive $\mathrm{T}$ cells admixed with numerous CD20-positive $\mathrm{T}$ cells. The $\mathrm{T}$ cells express CD4 and are negative for CD8. A T-follicular helper (TFH) phenotype was reported for these lesions, with frequent expression of PD1 (exhibiting a "rosette" pattern), CXCL13, and bcl-6
$[53,54]$. About $60 \%$ of the cases were demonstrated to be clonal by TCR gene rearrangement analysis in a large series of cases [51], and genetic aberrations have not be identified to date [55].

TFH phenotype may also be encountered in primary cutaneous T-cell lymphomas, NOS. Malignant tumors with TFH phenotype are not yet included as a separate category in the current WHO classification, and it is unclear if TFH phenotype confers any diagnostic or prognostic information per se.

\section{Conclusions}

T-cell lymphomas and lymphocytic proliferations in the skin may signify a significant challenge on histopathological examination. When putting all the pieces together, it is advisable to think of common clinical presentations, to be aware of clue histopathological features, and to interpret results of ancillary studies in the context of clinical and pathological findings. Discussion of the case with the clinician is of utmost importance for a correct final diagnosis. As members of the multidisciplinary medical team in charge of diagnosing and treating patients, pathologists should not hesitate to express their concerns and ideas about the case, to request new biopsies, clinical information, and follow up.

Acknowledgements We thank Jesus Navarrete Viveros, MD, Visiting Research Intern at the Dermatopathology Section, Department of Pathology, and Roberto N Miranda, MD, from the Hematopathology Department, The University of Texas MD Anderson Cancer Center, for their insightful comments and literature search in the preparation of this lecture. Adriana Torres-Li Ning helped proofreading this manuscript.

\section{Compliance with ethical standards}

Conflict of interest The author declares that they have no conflict of interest.

Publisher's note Springer Nature remains neutral with regard to jurisdictional claims in published maps and institutional affiliations.

\section{References}

1. Torres-Cabala CA, Curry JL, Chen SS, Miranda RN, Prieto V. Hematolymphoid proliferations of the skin. In: Precision Molecular Pathology of Dermatologic Diseases. New York: Springer; 2015. p. 3-36.

2. Willemze R, Cerroni L, Kempf W, Berti E, Facchetti F, Swerdlow SH, et al. The 2018 update of the WHO-EORTC classification for primary cutaneous lymphomas. Blood. 2019;133:1703-14.

3. Pimpinelli N, Olsen EA, Santucci M, Vonderheid E, Haeffner AC, Stevens S, et al. Defining early mycosis fungoides. J Am Acad Dermatol. 2005;53:1053-63. 
4. Vandergriff T, Nezafati KA, Susa J, Karai L, Sanguinetti A, Hynan LS, et al. Defining early mycosis fungoides: validation of a diagnostic algorithm proposed by the International Society for Cutaneous Lymphomas. J Cutan Pathol. 2015;42:318-28.

5. Nuckols JD, Shea CR, Horenstein MG, Burchette JL, Prieto VG. Quantitation of intraepidermal T-cell subsets in formalin-fixed, paraffin-embedded tissue helps in the diagnosis of mycosis fungoides. J Cutan Pathol. 1999;26:169-75.

6. Tebeica T, Andrei R, Zurac S, Staniceanu F. Practical aspects regarding the histopathological diagnosis of early mycosis fungoides. Rom J Intern Med. 2016;54:3-10.

7. Florell SR, Cessna M, Lundell RB, Boucher KM, Bowen GM, Harris RM, et al. Usefulness (or lack thereof) of immunophenotyping in atypical cutaneous T-cell infiltrates. Am J Clin Pathol. 2006;125:727-36.

8. Moll M, Reinhold U, Kukel S, Abken H, Muller R, Oltermann I, et al. CD7-negative helper T cells accumulate in inflammatory skin lesions. J Invest Dermatol. 1994;102:328-32.

9. Alessi E, Coggi A, Venegoni L, Merlo V, Gianotti R. The usefulness of clonality for the detection of cases clinically and/or histopathologically not recognized as cutaneous T-cell lymphoma. Br J Dermatol. 2005;153:368-71.

10. Guitart J, Magro C. Cutaneous T-cell lymphoid dyscrasia: a unifying term for idiopathic chronic dermatoses with persistent T-cell clones. Arch Dermatol. 2007;143:921-32.

11. Beylot-Barry M, Sibaud V, Thiebaut R, Vergier B, Beylot C, Delaunay M, et al. Evidence that an identical $\mathrm{T}$ cell clone in skin and peripheral blood lymphocytes is an independent prognostic factor in primary cutaneous T cell lymphomas. J Invest Dermatol. 2001;117:920-6.

12. Magro CM, Daniels BH, Crowson AN. Drug induced pseudolymphoma. Semin Diagn Pathol. 2018;35:247-59.

13. Huang Y, Litvinov IV, Wang Y, Su MW, Tu P, Jiang X, et al. Thymocyte selection-associated high mobility group box gene (TOX) is aberrantly over-expressed in mycosis fungoides and correlates with poor prognosis. Oncotarget. 2014;5:4418-25.

14. Zhang Y, Wang $\mathrm{Y}, \mathrm{Yu} \mathrm{R}$, Huang $\mathrm{Y}, \mathrm{Su} \mathrm{M}$, Xiao $\mathrm{C}$, et al. Molecular markers of early-stage mycosis fungoides. J Invest Dermatol. 2012;132:1698-706.

15. Yu X, Luo Y, Liu J, Liu Y, Sun Q. TOX acts an oncological role in mycosis fungoides. PLoS ONE. 2015;10:e0117479.

16. McGirt LY, Degesys CA, Johnson VE, Zic JA, Zwerner JP, Eischen CM. TOX expression and role in CTCL. J Eur Acad Dermatol Venereol. 2016;30:1497-502.

17. Yuki A, Shinkuma S, Hayashi R, Fujikawa H, Kato T, Homma E, et al. CADM1 is a diagnostic marker in early-stage mycosis fungoides: multicenter study of 58 cases. J Am Acad Dermatol. 2018;79:1039-46.

18. Sherman S, Rabizadeh E, Moyal L, Livnat T, Ziv E, Cherny I, et al. Fibrinogen-like protein 2 activity as a potential biomarker for diagnosis of early mycosis fungoides. Acta Derm Venereol. 2017:97:370-2.

19. Martinez-Escala ME, Kantor RW, Cices A, Zhou XA, Kaplan JB, Pro B, et al. CD8(+) mycosis fungoides: a low-grade lymphoproliferative disorder. J Am Acad Dermatol. 2017;77:489-96.

20. Tournier E, Laurent C, Thomas M, Meyer N, Viraben R, Brousset $P$, et al. Double-positive CD4/CD8 mycosis fungoides: a rarely reported immunohistochemical profile. J Cutan Pathol. 2014;41:58-62.

21. Hodak E, David M, Maron L, Aviram A, Kaganovsky E, Feinmesser M. CD4/CD8 double-negative epidermotropic cutaneous T-cell lymphoma: an immunohistochemical variant of mycosis fungoides. J Am Acad Dermatol. 2006;55:276-84.

22. Aung PP, Climent F, Muzzafar T, Curry JL, Patel KP, Servitje O, et al. Immunophenotypic shift of CD4 and CD8 antigen expression in primary cutaneous T-cell lymphomas: a clinicopathologic study of three cases. J Cutan Pathol. 2014;41:51-7.
23. Fauconneau A, Pham-Ledard A, Cappellen D, Frison E, Prochazkova-Carlotti M, Parrens M, et al. Assessment of diagnostic criteria between primary cutaneous anaplastic large-cell lymphoma and CD30-rich transformed mycosis fungoides; a study of 66 cases. Br J Dermatol. 2015;172:1547-54.

24. Hsi AC, Lee SJ, Rosman IS, Carson KR, Kelley A, Viele V, et al. Expression of helper $\mathrm{T}$ cell master regulators in inflammatory dermatoses and primary cutaneous T-cell lymphomas: diagnostic implications. J Am Acad Dermatol. 2015;72:159-67.

25. Kempf W. A new era for cutaneous CD30-positive T-cell lymphoproliferative disorders. Semin Diagn Pathol. 2017;34:22-35.

26. Saggini A, Gulia A, Argenyi Z, Fink-Puches R, Lissia A, Magana $\mathrm{M}$, et al. A variant of lymphomatoid papulosis simulating primary cutaneous aggressive epidermotropic CD8+ cytotoxic T-cell lymphoma. Description of 9 cases. Am J Surg Pathol. 2010;34:1168-75.

27. Andersen RM, Larsen MS, Poulsen TS, Lauritzen AF, Skov L. Lymphomatoid papulosis type D or an aggressive epidermotropic CD8(+) cytotoxic T-cell lymphoma? Acta Derm Venereol. 2014;94:474-5.

28. Berti E, Tomasini D, Vermeer MH, Meijer CJ, Alessi E, Willemze R. Primary cutaneous CD8-positive epidermotropic cytotoxic T cell lymphomas. A distinct clinicopathological entity with an aggressive clinical behavior. Am J Pathol. 1999;155:483-92.

29. McQuitty E, Curry JL, Tetzlaff MT, Prieto VG, Duvic M, TorresCabala C. The differential diagnosis of CD8-positive ("type D") lymphomatoid papulosis. J Cutan Pathol. 2014;41:88-100.

30. Rodriguez-Pinilla SM, Ortiz-Romero PL, Monsalvez V, Tomas IE, Almagro M, Sevilla A, et al. TCR-gamma expression in primary cutaneous T-cell lymphomas. Am J Surg Pathol. 2013;37:375-84.

31. Kempf W, Kazakov DV, Scharer L, Rutten A, Mentzel T, Paredes $\mathrm{BE}$, et al. Angioinvasive lymphomatoid papulosis: a new variant simulating aggressive lymphomas. Am J Surg Pathol. 2013;37:1-13.

32. Pierard GE, Ackerman AB, Lapiere CM. Follicular lymphomatoid papulosis. Am J Dermatopathol. 1980;2:173-80.

33. Karai LJ, Kadin ME, Hsi ED, Sluzevich JC, Ketterling RP, Knudson RA, et al. Chromosomal rearrangements of $6 \mathrm{p} 25.3$ define a new subtype of lymphomatoid papulosis. Am J Surg Pathol. 2013;37:1173-81.

34. Cerroni L. Past, present and future of cutaneous lymphomas. Semin Diagn Pathol. 2017;34:3-14.

35. Willemze R, Beljaards RC. Spectrum of primary cutaneous CD30 (Ki-1)-positive lymphoproliferative disorders. A proposal for classification and guidelines for management and treatment. J Am Acad Dermatol. 1993;28:973-80.

36. Kadin ME, Pinkus JL, Pinkus GS, Duran IH, Fuller CE, Onciu M, et al. Primary cutaneous ALCL with phosphorylated/activated cytoplasmic ALK and novel phenotype: EMA/MUC1+, cutaneous lymphocyte antigen negative. Am J Surg Pathol. 2008;32:1421-6.

37. Geller S, Canavan TN, Pulitzer M, Moskowitz AJ, Myskowski PL. ALK-positive primary cutaneous anaplastic large cell lymphoma: a case report and review of the literature. Int J Dermatol. 2018;57:515-20.

38. Quintanilla-Martinez L, Ridaura C, Nagl F, Saez-de-Ocariz M, Duran-McKinster C, Ruiz-Maldonado R, et al. Hydroa vacciniforme-like lymphoma: a chronic EBV+ lymphoproliferative disorder with risk to develop a systemic lymphoma. Blood. 2013;122:3101-10.

39. Magana M, Sangueza P, Gil-Beristain J, Sanchez-Sosa S, Salgado A, Ramon G, et al. Angiocentric cutaneous T-cell lymphoma of childhood (hydroa-like lymphoma): a distinctive type of cutaneous T-cell lymphoma. J Am Acad Dermatol. 1998;38:574-9.

40. Barrionuevo C, Anderson VM, Zevallos-Giampietri E, Zaharia M, Misad O, Bravo F, et al. Hydroa-like cutaneous T-cell lymphoma: a clinicopathologic and molecular genetic study of 16 pediatric cases from Peru. Appl Immunohistochem Mol Morphol. 2002;10:7-14. 
41. Wen PF, Liu H. Hydroa vacciniforme-like cutaneous T-cell lymphoma in an adult presenting with facial edema and recurrent oral ulceration. Am J Dermatopathol. 2018;40:227-9.

42. Magana M, Massone C, Magana P, Cerroni L. Clinicopathologic features of hydroa vacciniforme-like lymphoma: a series of 9 patients. Am J Dermatopathol. 2016;38:20-5.

43. Toro JR, Beaty M, Sorbara L, Turner ML, White J, Kingma DW, et al. gamma delta T-cell lymphoma of the skin: a clinical, microscopic, and molecular study. Arch Dermatol. 2000;136:1024-32.

44. Willemze R, Jansen PM, Cerroni L, Berti E, Santucci M, Assaf C, et al. Subcutaneous panniculitis-like T-cell lymphoma: definition, classification, and prognostic factors: an EORTC cutaneous lymphoma group study of 83 cases. Blood. 2008;111:838-45.

45. Ramani NS, Curry JL, Merrill ED, Aung PP, Prieto V, Tetzlaff MT, et al. Primary cutaneous gamma-delta (gamma/delta) T-cell lymphoma: an unusual case with very subtle histopathological findings. Am J Dermatopathol. 2016;38:e147-9.

46. Merrill ED, Agbay R, Miranda RN, Aung PP, Tetzlaff MT, Young KH, et al. Primary cutaneous T-cell lymphomas showing gamma-delta (gammadelta) phenotype and predominantly epidermotropic pattern are clinicopathologically distinct from classic primary cutaneous gammadelta T-cell lymphomas. Am J Surg Pathol. 2017;41:204-15.

47. Jour G, Aung PP, Merrill ED, Curry JL, Tetzlaff MT, Nagarajan $\mathrm{P}$, et al. Differential expression of CCR4 in primary cutaneous gamma/delta (gammadelta) T cell lymphomas and mycosis fungoides: significance for diagnosis and therapy. J Dermatol Sci. 2018;89:88-91.

48. Agbay RL, Torres-Cabala CA, Patel KP, Merril ED, Duvic M, Quesada A, et al. Immunophenotypic shifts in primary cutaneous gammadelta T-cell lymphoma suggest antigenic modulation: a study of sequential biopsy specimens. Am J Surg Pathol. 2017; 41:431-45.

49. Petrella T, Maubec E, Cornillet-Lefebvre P, Willemze R, Pluot M, Durlach A, et al. Indolent CD8-positive lymphoid proliferation of the ear: a distinct primary cutaneous T-cell lymphoma? Am J Surg Pathol. 2007;31:1887-92.

50. Beltraminelli H, Mullegger R, Cerroni L. Indolent CD8+ lymphoid proliferation of the ear: a phenotypic variant of the small-medium pleomorphic cutaneous T-cell lymphoma? J Cutan Pathol. 2010; 37:81-4.

51. Beltraminelli H, Leinweber B, Kerl H, Cerroni L. Primary cutaneous CD4+ small-/medium-sized pleomorphic T-cell lymphoma: a cutaneous nodular proliferation of pleomorphic T lymphocytes of undetermined significance? A study of 136 cases. Am J Dermatopathol. 2009;31:317-22.

52. Berti E, Willemze, R, Guitart, J, Jaffe, ES, Kempf, W, Petrella, T, et al. Primary cutaneous peripheral T-cell lymphomas, rare subtypes, In: Elder D, Massi, D, Scolyer, R, Willemze, R, editors. WHO classification of skin tumors. 4th edn. Lyon: International Agency for Research on Cancer; 2018. p. 248-53.

53. Rodriguez Pinilla SM, Roncador G, Rodriguez-Peralto JL, Mollejo M, Garcia JF, Montes-Moreno S, et al. Primary cutaneous CD4+ small/medium-sized pleomorphic T-cell lymphoma expresses follicular T-cell markers. Am J Surg Pathol. 2009;33:81-90.

54. Williams VL, Torres-Cabala CA, Duvic M. Primary cutaneous small- to medium-sized CD4+ pleomorphic T-cell lymphoma: a retrospective case series and review of the provisional cutaneous lymphoma category. Am J Clin Dermatol. 2011;12:389-401.

55. Alberti-Violetti S, Torres-Cabala CA, Talpur R, Corti L, Fanoni $\mathrm{D}$, Venegoni L, et al. Clinicopathological and molecular study of primary cutaneous CD4+ small/medium-sized pleomorphic T-cell lymphoma. J Cutan Pathol. 2016;43:1121-30. 